\title{
INTERDISCURSIVIDADE E TEORIA DA ICONICIDADE VERBAL NAS FÁBULAS FABULOSAS
}

Elmar Rosa de Aquino (UERJ)

"Quando alguém pergunta a um autor o que este quis dizer, é porque um dos dois é burro."

Mário Quintana

Resumo: Este artigo pretende fazer uma análise interdiscursiva de uma versão do conto de Chapeuzinho Vermelho pertencente à série Fábulas Fabulosas, de Millôr Fernandes, pela perspectiva semiótico-discursiva proposta por Darcilia Simões (2009), a partir da Teoria da Iconicidade Verbal. Nesse viés, procura-se trazer discussões acerca do problema do analfabetismo funcional e suas consequências na proficiência de leitura e de produção textual dos alunos.

Palavras-chave: Analfabetismo funcional. Interdiscursividade. Iconicidade verbal. Leitura. Produção textual.

Abstract: This article intends to make an interdiscursive analysis of a version of the ChapeuzinhoVermelho story belonging to the series Fábulas Fabulosas, by Millôr Fernandes, through the semiotic-discursive perspective proposed by Darcilia Simões, from the Theory of Verbal Iconicity. In this bias, we seek to bring discussions about the problem of functional illiteracy and its consequences on students' reading proficiency and textual production.

Keywords: Functional illiteracy. Interdiscursivity. Verbal iconicity. Reading. Textual production.

Acreditamos que o ensino de leitura com vista à formação de leitores críticos e autônomos possa ter maior produtividade caso as teorias que focalizam as relações interpessoais sejam aplicadas como metodologia de trabalho para a análise dos mais diversos gêneros textuais que circulam em nossa sociedade. E que se 
extraia desses textos a maior quantidade de conteúdo informativo possível.

Na nossa prática pedagógica, temos observado as diversas maneiras como as ideias vêm sendo construídas e veiculadas linguisticamente, seja pelos meios de comunicação institucionalizados, seja pelos usuários comuns da língua, o que, a nosso ver, constitui-se em um processo de aproximação do que podemos chamar de interdiscursividade.

A grande dificuldade com que os estudantes conseguem chegar ao final do nível médio sem ter desenvolvido habilidades básicas de leitura e escrita é uma de nossas principais preocupações.

Sobre esse aspecto, em matéria publicada em novembro de 2012, na Revista Educação, a jornalista Luciana Alvarez, afirma que:

Eles [os estudantes] frequentaram os bancos escolares por no mínimo nove anos, passaram por dezenas de professores diferentes, fizeram provas, trabalhos, diversas avaliações internas e externas. Ainda assim, dados do Indicador Nacional de Alfabetismo Funcional (INAF) divulgados recentemente apontam que $8 \%$ dos jovens que chegaram ao ensino médio no Brasil são considerados analfabetos funcionais, ou seja, têm um conhecimento apenas rudimentar da língua escrita, não conseguem ler e entender textos de média extensão, 
nem fazer pequenas inferências. [...] Como essas crianças conseguiram passar tantos anos nos bancos escolares sem aprender? E por que não aprenderam? (ALVAREZ, 2012)

Segundo a pesquisa amostral feita para medir o Indicador Nacional de Alfabetismo Funcional (INAF), o primeiro nível seria o "analfabetismo total ou absoluto", que caracteriza o indivíduo incapaz de ler palavras ou frases. Já o segundo nível refere-se ao "analfabetismo funcional", no qual o leitor consegue localizar informações explícitas em textos curtos e familiares. Quando este atinge o nível de compreensão de textos de média extensão, localiza informações e faz pequenas inferências, está incluído no terceiro nível, ou seja, o "básico". O último grau da escala estabelecida pelo INAF é o "alfabetismo pleno", que deveria ser alcançado por todos os concluintes do ensino fundamental, sendo estes, então, capazes de ler textos usuais mais longos, como uma notícia de jornal ou uma peça publicitária, analisar e relacionar suas partes e distinguir fato e opinião.

A exposição a textos que se entrecruzam e formam uma grande rede interdiscursiva poderá ajudar na compreensão e apreensão das modalidades estilísticas, bem como no estímulo à produção textual de nossos alunos. Para tanto, é preciso primeiramente que estes entendam que, antes de 
mergulhar na mais profunda análise dos sentidos possíveis, desencadeados pelos textos, é necessário o domínio linguístico, considerando-se as alternativas oferecidas pelo sistema da língua. Pois, sem esse domínio, as possibilidades de leitura e produção de sentidos poderão limitar-se à estruturação superficial do texto.

Segundo pesquisadores da área de educação, o analfabetismo funcional é caracterizado pela capacidade precária de um indivíduo - que detém conhecimentos de leitura e escrita - em conseguir concatenar as ideias presentes nos textos. Em outras palavras, de acordo com o pesquisador Wagner (2000, p. 18), “a alfabetização é, antes de mais nada, um fenômeno cultural e, como tal, é praticada em situações e contextos de grande diversidade". Em sua obra intitulada Alfabetização: construir o futuro, esse autor faz um breve panorama da história do alfabetismo ao longo dos séculos de desenvolvimento do conhecimento humano, afirmando que "o mais impressionante nos textos históricos relativos ao alfabetismo é a importância atribuída, nos séculos passados, à leitura e à escrita, geralmente consideradas como duas atividades distintas" (WAGNER, 2000, p. 18). Entretanto, tais atividades estariam relacionadas ao poder social e moral veiculado pelo clero das grandes religiões, 
as quais detinham uma ou ambas as aptidões, do que se poderia denominar "alfabetismo religioso", desde antes da Grécia Antiga até a Idade Média (WAGNER, 2000, p. 18). Sua história ainda acumula as transformações sociais e religiosas, como a criação da escola pública, o desenvolvimento de uma democracia e das revoluções sociais.

Sobre tal ênfase dada ao ensino das letras, Wagner nos diz que:

Durante muito tempo aceitou-se a ideia de que o aumento dos índices de alfabetização e dos níveis de educação da população eram as causas fundamentais do crescimento econômico. As pesquisas atuais tendem a contradizer essa afirmação. Em alguns países, como a Suécia, os altos níveis de alfabetização existiam muito antes de que se produzisse a revolução industrial. Inversamente, o Reino Unido apresentava, nesse campo, taxas relativamente baixas, inclusive durante os períodos de rápido crescimento econômico. As possibilidades de educação e de alfabetização aumentaram, segundo parece, graças ao desenvolvimento tecnológico, que permitiu a escolarização das crianças durante um período mais prolongado. (2000, p. 19)

Nesse aspecto, a história da alfabetização, aqui vista como o aprendizado da leitura e da escrita, tem como uma de suas consequências a formação de uma visão crítica acerca 
das estratégias de manipulação exercidas pelas classes dominantes, seja economicamente, seja culturalmente. Por esse motivo, o empenho para a difusão do domínio desses conhecimentos se faz presente nas sociedades letradas, principalmente por parte das pessoas já alfabetizadas. Nesse sentido, Wagner (2000, p. 20) assevera que "esses esforços de alfabetização exigiram muitos anos de determinação firme, às vezes sob regimes políticos diferentes, com visões políticas diversas", fator determinante para a redução do analfabetismo e para a criação de uma sociedade em que todos tivessem acesso ao conhecimento.

Para Vera Masagão Ribeiro, Doutora em Educação pela PUC-SP e coordenadora da ONG Ação Educativa,

em todo o mundo, a modernização das sociedades, o desenvolvimento tecnológico, a ampliação da participação social e política colocam demandas cada vez maiores com relação às habilidades de leitura e escrita. A questão não é mais apenas saber se as pessoas conseguem ou não ler e escrever, mas também o que elas são capazes de fazer com essas habilidades. Isso quer dizer que, além da preocupação com o analfabetismo, problema que ainda persiste nos países mais pobres e também no Brasil, emerge a preocupação com o alfabetismo, ou seja, com as capacidades e usos efetivos da leitura e escrita nas diferentes esferas da vida social. (RIBEIRO, 2014, grifos da autora) 
Nessa perspectiva, a pesquisadora observa que o fato de ter concluído o primeiro segmento do ensino fundamental não garante o status de alfabetismo funcional. Esse conceito é relativo e está atrelado a variados domínios voltados para a leitura e a escrita, de acordo com os contextos e as expectativas da sociedade em que o indivíduo está inserido e das competências mínimas exigidas.

Segundo Wood Jr.,

Uma variação do analfabetismo funcional parece estar presente no topo da pirâmide corporativa e na academia. Em uma longa série de entrevistas realizadas por este escriba, nos últimos cinco anos, com diretores de grandes empresas locais, uma queixa revelou-se rotineira: falta a muitos profissionais da média gerência a capacidade de interpretar de forma sistemática situações de trabalho, relacionar devidamente causas e efeitos, encontrar soluções e comunicá-las de forma estruturada. Não se trata apenas de usar corretamente o vernáculo, mas de saber tratar informações e dados de maneira lógica e expressar ideias e proposições de forma inteligível, com começo, meio e fim. (2014)

Com essa afirmação, o autor observa um novo paradigma para a condição do analfabetismo funcional, agora relacionado às camadas mais elevadas culturalmente. Ou seja, apesar de, supostamente, deter um volume maior 
de conhecimentos formais e de dispor de tecnologia avançada, ao deparar com a necessidade de produzir textos que expressem suas ideias de maneira clara e coerente, o usuário da língua não demonstra desenvoltura suficiente para lidar com a escrita formal. E essa dificuldade aparece entre os alunos dos cursos de MBA (Master in Business Administration), mestrado e doutorado.

Cabe trazer, aqui, um relato de experiência pessoal como ouvinte em uma banca de mestrado, na qual um dos membros, com menos experiência e menos tempo exercendo a atividade de professor em uma universidade pública, fizera um comentário sobre a produção textual da dissertação, afirmando que esta necessitava de uma revisão acerca dos mecanismos de coesão, com ênfase na pontuação, que causavam dificuldades quanto ao entendimento do texto. O que me causou estranheza foi o fato de o segundo membro da banca, o qual pertencia à mesma instituição de ensino em que se formava a mestranda e tinha mais experiência acadêmica, inclusive com vários trabalhos e livros publicados, ter discordado do primeiro, tendo em vista que este defendia o argumento de que o trabalho de pesquisa estava excelente e que a exigência de uma revisão para tornar o texto mais claro e 
de acordo com as normas gramaticais adequadas àquele gênero textual seria desnecessária.

Parte dos problemas relacionados ao desinteresse acerca da proficiência linguística, tanto de alunos quanto de professores, está ligada ao ensino da gramática. Em países como Alemanha, França, Inglaterra, Espanha, Itália, grandes centros econômicos e culturais do mundo moderno, a gramática considerada básica, que existe em qualquer língua, continua a ser ensinada em concomitância com as teorias da Linguística, inclusive as da Análise de Texto e de Discurso, a Literatura etc. (RICINO, 2013). Porém, com uma nova metodologia, diferente da que era utilizada há trinta ou quarenta anos atrás. Segundo Eleomar Rosetti Ricino,

$$
\begin{aligned}
& \text { essa nova roupagem do ensino, essa } \\
& \text { adaptação aos novos tempos, no caso } \\
& \text { brasileiro, significa praticamente a } \\
& \text { eliminação da gramática do currículo } \\
& \text { escolar. Pincela-se aqui, pincela-se acolá } \\
& \text { algum elemento gramatical, jogado ao } \\
& \text { aluno aleatoriamente, sem sequência, sem } \\
& \text { respaldo, sem taxonomia, sem ênfase, isto } \\
& \text { é, de forma caótica, com o desinteresse } \\
& \text { típico de quem acha que aquilo não tem a } \\
& \text { menor importância, é assunto insignificante. }
\end{aligned}
$$
(2013, p. 34)

Sob essa perspectiva, o autor assevera que, no Brasil, diferentemente dos países já citados, está havendo um 
absurdo e irresponsável abandono do ensino da gramática. E, aí, fazemos um questionamento acerca desse problema: pode a escrita, que é uma das maiores invenções da humanidade, sobreviver sem a "supervisão" de uma gramática?

Quando voltamos nosso olhar para o leitor, que parte dos elementos da superfície do texto para a construção do sentido - ou sentidos -, para a interpretação do texto, constata-se a importância de aproveitarem-se seus conhecimentos prévios e experiências acumuladas ao longo de sua história como subsídios para a tarefa de leitura com compreensão. O leitor proficiente será aquele capaz de seguir as pistas textuais oferecidas pelo enunciador, sem se prender a uma leitura única, quase sempre proposta ou abalizada por uma "autoridade". Isso ocorre, principalmente nas leituras que privilegiam (ou determinam) uma direção exclusiva de leitura, em detrimento de uma percepção das qualidades polissêmicas do texto, das interpretações a que os textos dão margem (semiose ilimitada, para PEIRCE, apud ECO, 1980, p. 60).

Segundo Simões, "os textos, em última análise, materializam nossos pensamentos, que são interpretação dos fenômenos que se nos apresentam" (2007, p. 15). Além disso, "o objeto-texto não se apresenta acabado e será 
reconstruído a cada leitura, demonstrando de modo pleno o que se chama tecnicamente de semiose ilimitada".

$\mathrm{Na}$ nossa prática pedagógica, temos observado as diversas maneiras como as ideias vêm sendo construídas e veiculadas linguisticamente, seja pelos meios de comunicação institucionalizados, seja pelos usuários comuns da língua, o que, a nosso ver, constitui-se em um processo de aproximação do que podemos chamar de intersemiose (cf. SIMÕES, 2007), ou seja, quando a semiose (cf. PEIRCE, 2005) manifesta-se nas relações dialógicas e interpessoais. Relações estas definidas a partir dos estudos sobre a funcionalidade da língua.

Segundo Marcuschi, Halliday "amplia suas linhas de observação para o plano do texto na relação com o contexto, desenvolvendo reflexões sistemáticas a respeito do funcionamento do sistema na sua relação com o contexto situacional" (2008, p. 33). A partir das propostas de Halliday, combinadas com as teorias de Bakhtin e Vygotsky, o autor sugere um modelo de reflexão sobre a sociointeratividade sob quatro aspectos, a saber:

(a) na noção de linguagem como atividade social e interativa;

(b) na visão de texto como unidade de sentido ou unidade de interação; 
(c) na noção de compreensão como atividade de construção de sentido na relação de um eu e um tu situados e mediados e

(d) na noção de gênero textual como forma de ação social e não como entidade linguística formalmente constituída. (MARCUSCHI, 2008 , p. 21, grifos do autor)

Com base nesses pressupostos, podemos entender 0 mecanismo de produção de sentidos como uma atividade que não se restringe apenas ao produtor do texto determinismo internalista - nem ao contexto social determinismo externalista (cf. MARCUSCHI, 2008).

Como nos diz Simões, "a interação mente e signo é dinâmica, por conseguinte, mutante. Logo, se o texto é signo, está sujeito à mesma dinâmica e mutabilidade das funções e valores carregados pelos signos e deles emergentes segundo o momento de produção de leitura" (2007, p. 18), daí a possibilidade de adaptação do texto clássico a uma linguagem mais moderna, atual. Caso o leitor detenha os conhecimentos necessários para promover uma leitura calcada na interdiscursividade - a partir do reconhecimento do texto clássico, pela intertextualidade - poderá fazer inferências que o levem a outros caminhos na interpretação. A intertextualidade poderia servir como um dos signos orientadores para a leitura do texto. 
A iconicidade textual, resultante das semelhanças entre as versões, é o fio condutor com potencial de gerar "imagens na mente interpretadora, a partir das quais seja possível aproximar-se do projeto comunicativo inscrito no texto" (SIMÕES, 2007, p. 19). Essa gama de possibilidades se dá porque "a leitura de textos procede de uma negociação entre imagens mentais construídas por um enunciador e reconstruídas por um coenunciador (leitor ou intérprete)" e "[...] a plasticidade textual é referência de iconicidade e pode funcionar como base para a condução do intérprete à mensagem básica inscrita no texto" (SIMÕES, 2007, p. 19-20, grifos da autora).

Nessa perspectiva, podemos aplicar o conceito de interdiscursividade como fator determinante para a condução e produção dos sentidos, já que:

A produção textual trilha um caminho complexo, por reunir numa mesma superfície signos de tipos variados cuja carga semiótica é individual (do ponto de vista da escolha do enunciador) e interindividual (considerada a sua pertinência a um sistema históricocultural). (SIMÕES, 2007, p. 20)

Segundo Frege, "se produzimos um sinal para uma ideia que uma percepção trouxe à mente, criamos com isto um novo núcleo estável em torno do qual se reúnem outras 
ideias. Entre estas, podemos escolher novamente uma outra [ideia], para ela criar seu sinal" (2009, p. 60). Com essa definição, Frege nos esclarece como se dá o processo de semiotização das coisas, ou seja, a transformação dos objetos-de-mundo em objetos-de-discurso. Dessa forma, a criação dos signos que irão servir à produção das linguagens e, por conseguinte, à produção do pensamento, dá origem ao processo comunicativo.

Para o filósofo, a observação da gramática não é suficiente para a construção do pensamento, é necessário que se atente para a variabilidade das inferências, pois a linguagem não é regida por leis lógicas. Sob esse aspecto, o ensino de gramática sem uma preocupação com a origem dos fenômenos a ela relacionados - como o contexto de produção do texto e os fatores pragmáticos - tornase inócuo a uma construção dos sentidos imanente ao próprio uso da gramática, já que esta também está sujeita a variações de ordem sócio-histórica, ou mesmo à intenção comunicativa do produtor do texto. Assim, ressalte-se a importância do conhecimento das estruturas gramaticais para a compreensão dos efeitos de sentido determinados por estas, na relação com o contexto situacional.

Segundo Frege, 
a conexão regular entre um sinal, seu sentido e sua referência é de tal modo que ao sinal corresponde um sentido determinado e ao sentido, por sua vez, corresponde uma referência determinada, enquanto que uma referência (um objeto) pode receber mais de um sinal. E ainda, um mesmo sentido tem em diferentes linguagens, ou até na mesma linguagem, diferentes expressões. (2009, p. 132)

O que estabelece a relação entre a expressão e seu referente é o sentido. Mas o sentido de uma expressão não está atrelado necessariamente a uma realidade linguística, e também não se caracteriza, subjetivamente, na forma de uma ideia, e menos ainda de um objeto. O sentido de uma expressão não depende de um referente ([Nota do tradutor] cf. FREGE, 2009, p. 132).

O filósofo faz ainda uma distinção entre "sentido e referências costumeiras" e "sentido e referências indiretas", para assim preservar a possibilidade de substituição das expressões que têm a mesma referência. A referência costumeira ocorre no discurso direto, ou seja, na sua forma usual, de referência habitual. Já a referência indireta acontece como no discurso indireto: para falar das próprias palavras, citadas de outrem, ou para falar do seu sentido. Por assim dizer, a referência e o sentido são distintos da ideia associada ao sinal. "Quando a referência de um sinal 
é um objeto sensorialmente perceptível, então a ideia que dele tenho é uma imagem interna, emersa das lembranças de impressões sensíveis passadas e das atividades, internas e externas, que realizei" (FREGE, 2009, p. 134), o que depende do conhecimento de mundo de cada indivíduo, fazendo da referência um dado subjetivo. Inclusive, não há uma obrigatoriedade de que, na mesma mente, sejam encontradas ideias correspondentes aos mesmos sentidos. Esse aspecto polissêmico torna variável a relação entre ideia e sentido. Sendo assim, a referência estaria para o objeto, como o sentido para o interpretante, na semiótica de Peirce (2005).

De acordo com Bourdieu,

a lógica do sistema de atos e procedimentos expressivos não pode ser compreendida independentemente de sua função, que é dar uma tradução simbólica do sistema social "como sistema de inclusão e de exclusão", segundo a expressão de McGuire, mas também, significar a comunidade e a distinção transmutando os bens econômicos em signos e as ações orientadas para fins econômicos em atos de comunicação (que podem exprimir inclusive a recusa de comunicar). (1999, p. 17)

Nesse sentido, a expressão do pensamento não pode desvincular-se do fator social que a linguagem pressupõe, 
considerando-se o contexto sócio-histórico e as condições de produção. Assim, os signos servem para a construção do universo cognitivo e também para o estabelecimento de processos comunicativos, respeitadas as convenções que, conforme Weber (apud BOURDIEU, 1999, p. 16) aponta, "os grupos de status são os portadores de todas as 'convenções': toda estilização da vida, seja qual for a forma sob a qual se manifesta, tem sua origem num grupo de status ou é mantida viva por um grupo de status" (grifo do autor). Portanto, nas sociedades tradicionais, os grupos de status impõem aos seus membros modelos de comportamento e regras convencionais definidoras da maneira como se devem executar tais modelos.

A Teoria da Iconicidade Verbal de Simões (2009) traz sua contribuição no que tange ao caráter icônico-indicial da diagramação do texto, além do estilo e da seleção vocabular, na construção da malha textual, configurando-se como pistas que orientam ou desorientam o leitor, porque exigem deste o domínio da gramática da língua e do conteúdo abordado pelo texto. Sendo assim, “a leitura (em sentido restrito) do texto estruturado em linguagem verbal é mais complexa, em princípio, e requer uma prática efetiva e intensiva, de modo que sejam adquiridas habilidades fundamentais que favoreçam sua eficiência" (SIMÕES, 2003, p. 27). 
Além dessas características, podemos considerar, como Simões (2003, p. 34), o processo da comunicação, em que se relacionam não apenas o sujeito (leitor) com o conteúdo de um dado texto (seus elementos de significação), mas com sua natureza, o tipo de estrutura que forma o tecido do texto, e que pode determinar a maior ou menor possibilidade de compreensão, porque é de máxima importância para o leitor a natureza e a realidade material (o código usado na cifração) da mensagem que lhe cabe interpretar.

Sendo assim, entendemos a bagagem cognitiva do leitor como um dos fatores fundamentais para uma leitura contextualizada e crítica. A partir desses fatores, é possível caracterizar o leitor crítico e autônomo como aquele que se mostra capaz de perceber, em maior ou menor grau, as estratégias argumentativas presentes nos textos, literários ou não. A produção textual é, por princípio, a expressão de ideias, logo, independentemente do código eleito, a distribuição dos signos no texto (seja oral, seja escrito; seja verbal, seja não verbal) configura uma forma de agir sobre o outro e, de alguma maneira, tentar persuadir o interlocutor a aceitar sua ideia. Logo, o texto é, por princípio, um objeto argumentativo.

Segundo Koch, 
os objetos-de-discurso não se confundem com a realidade extralinguística, mas (re) constroem-na no próprio processo de interação: a realidade é construída, mantida e alterada não apenas pela forma como nomeamos o mundo, mas, acima de tudo, pela forma como, sociocognitivamente, interagimos como ele. (2005, p. 33)

Temos, então, que a relação entre objetos-de-mundo e objetos-de-discurso não é direta, mas intermediada pela própria interação dos sujeitos discursivos que dependem de uma história, de uma cultura, de um sistema linguístico para operar esse processo de transformação, que nem sempre é compartilhado por todos os membros do grupo, gerando os equívocos.

Conforme Roncarati, "as estratégias cognitivas nos permitem efetuar cálculos mentais e inferências, com base nos quais construímos representações mentais que criam links entre conteúdos explícitos e implícitos no texto" (2010, p. 18). Sendo assim, basta a inserção de itens lexicais que remetam a conhecimentos compartilhados entre os interlocutores para que haja o entendimento do texto. Mas, para isso, é preciso uma bagagem cognitiva e a competência leitora para que se resgatem os sentidos possíveis presentes na composição textual.

Se os participantes da comunicação apresentam os conhecimentos necessários à ativação dos possíveis referentes, 
por meio da enunciação dos itens lexicais remissivos, a constituição semântica do texto se realiza de forma plena. Ademais, um referente pode aparecer uma vez no texto e ser descartado mais adiante, ou ser retomado por meio de pronomes, repetições, sinônimos ou, ainda, permanecer elíptico. Pode, também, dar origem a novos referentes por associação, formando uma cadeia multilinear ou multirreferencial, ou apenas unir-se a outros referentes (RONCARATI, 2010, p. 23), promovendo uma interseção referencial, num processo dinâmico e criativo de formação de cadeias referenciais, já que os sentidos nunca se esgotam, reajustando-se a novas interpretações.

Segundo ponderações de Aristóteles,

$$
\begin{aligned}
& \text { como não é possível trazer à colação as coisas } \\
& \text { em ato, e em vez delas temos de nos servir } \\
& \text { dos seus nomes como símbolos, supomos } \\
& \text { que o que se passa com os nomes se passa } \\
& \text { também com as coisas [...] entre nomes e } \\
& \text { objetos, não há semelhança total: os nomes } \\
& \text { são em número limitado, bem como a } \\
& \text { pluralidade das definições, mas as coisas são } \\
& \text { em número infinito. (2000, p. 79-80) }
\end{aligned}
$$

Nesse caso, os processos de (re)construção dos sentidos perpassariam as habilidades de se fazerem referências (endofóricas ou exofóricas) na busca pelas possibilidades de leitura, das quais emanaria uma infinidade de interpretações possíveis. 
Podemos observar que muitos textos produzidos ao longo dos milênios de evolução da humanidade procuram apresentar argumentos por meio dos mais diversos gêneros, dos mais realistas aos mais fantásticos, da crônica clássica à crônica moderna, da parábola à paródia, da fábula ao conto, todos a serviço da formação de ideologia. Além disso, também podemos perceber que há textos que procuram veicular argumentos para formação de uma visão crítica, levando os leitores a interpretarem a realidade, mesmo que seja por meio da fantasia, e assim promover mudanças. Mas não mudanças que visem aos interesses pessoais, em detrimento da coletividade.

Exemplos de histórias como Chapeuzinho Vermelho, em que, por trás de uma narrativa aparentemente inocente mais conhecida como supostamente voltada para um público infantil (ou infanto-juvenil, dependendo da versão) - reside um interesse retórico-argumentativo de defender a tese acerca das consequências da desobediência dos filhos em relação aos pais, do desvio das normas de conduta vigentes, do falar com estranhos e da quebra dos padrões tradicionais representados pela figura da Vovó, sugerem como o ato de reescritura desses textos também demonstra a preocupação dos autores com a adaptação ou reformulação dos valores 
apresentados nos textos originais, de acordo com seus pontos de vista (DEELY, 1990).

Um novo texto (mesmo parafraseado ou parodiado) gera não só novos referentes, como também possibilidades de novas inferências, as quais poderão servir como signos orientadores ou desorientadores (SIMÕES, 2007, p. 46) para os leitores. Assim, a partir da retomada temática de antigas fábulas, Millôr Fernandes "reinventa" a moral ao retextualizar essas alegorias, construindo assim uma ponte entre o clássico e o popular.

Segundo Ricoeur, "as palavras não têm significação própria, porque elas não têm a significação como própria; não possuem nenhum sentido em si mesmas, porquanto é o discurso, tomado como um todo, que transmite o sentido de maneira indivisa" (2000, p. 124). Se os significados, assim como os sentidos, estivessem presos às palavras, qualquer texto poderia ser lido e entendido por qualquer pessoa, independentemente de seu nível sociocultural, bastando apenas recorrer ao dicionário. E esse aspecto da leitura fica mais evidente quando se trata de uma tradução de texto em língua estrangeira.

Acerca das condições de verdade, Simões afirma que "o juízo de verossimilhança nada mais é do que um juízo de 
probabilidade construída por meio da coesão e da coerência na articulação dos signos que tecem o texto" (2007, p. 27) e, portanto, são estratégias utilizadas para o convencimento, sabendo-se que "o verossímil leva em conta que é melhor um argumento impossível que convença do que um possível que não convença; mesmo o irracional pode ser utilizado com aparência razoável de racional e tornar-se aceitável" (SIMÕES, 2007, p. 28-29).

Para Simões, o projeto de raciocínio dá origem à produção imagética por meio dos processos de dedução e indução, sendo que, "esta vai reunindo um a um os signos de que se constitui o texto de modo a compor o seu significado global; enquanto aquela parte do todo do texto e tenta decompôlo em partes menores que possam referendar a ideia global que Ihe fora atribuída" (2009, p. 84).

Dessa forma, o recurso epistemológico que o leitor/ouvinte ativa no processo de leitura determinaria as possibilidades de interpretação, as quais não seriam ilimitadas (ECO, 2004). Alguns termos, porém, perdem seu sentido original em detrimento dos novos sentidos que adquirem no uso popular e por consequência das influências religiosas, como os conceitos de superstição, bruxaria, mito, seita etc. As palavras encontram os referentes convencionados pela cultura. Por 
exemplo, a palavra diabo tem um sentido na cultura judaicocristã como uma personificação do mal (RICOEUR, 1988), mas também pode significar "mau-caráter", "pessoa de má índole"; já a expressão pobre diabo significa "pessoa insignificante, sem eira nem beira; pessoa de ânimo fraco, sem personalidade"1.

A partir do conceito de referência definido pela filosofia da linguagem e combinado com a teoria da iconicidade verbal por Simões, podemos observar uma relação entre a falta de domínio das estratégias de produção de sentidos realizadas entre produtor de texto e leitor, numa perspectiva dialógica, e as condições precárias do analfabetismo funcional.

Nessa concepção, entende-se que um dos fatores capazes de elevar os níveis de letramento - do mais rudimentar ao mais pleno -, considerada a capacidade de decifrar o código linguístico e interpretar mensagens, é a necessidade de se estabelecer a importância da extensão do vocabulário compartilhado e das formas de referenciação inerentes ao processo de semiotização dos objetos-de-mundo, nas práticas de leitura e produção de textos, sem perder de vista a questão da contextualização histórico-cultural.

Sendo assim, o leitor precisa estar atento às pistas fornecidas pelo produtor do texto para que possa fazer o

1 Disponível em: http://www.dicio.com.br/pobre-diabo/. Acesso em: 4. fev. 2015. 
maior número possível de inferências e, sob esse aspecto, consideramos que o reconhecimento dos diversos gêneros textuais, combinados com as estratégias de leitura baseadas na semiótica de extração peirciana, proporciona maior interação entre autor e leitor.

Além disso, a produção de sentidos, que toma como base significativa os fatores de interdiscursividade, auxilia no desvendamento do mundo e na compreensão dos jogos sígnicos gerados pelas associações do texto. E, ainda, como concretização do discurso que considera as condições de produção, os potenciais icônico e indicial do signo o fazem funcionar "como um vetor que indica caminhos possíveis na trilha textual" (SIMÕES, 2007, p. 21).

\section{ANÁLISE SEMIÓTICO-DISCURSIVA DE UMA VERSÃO DE MILLÔR FERNANDES PARA O CONTO CHAPEUZINHO VERMELHO}

Vovozinha Vermelha (e o Lobo não tão mau assim)

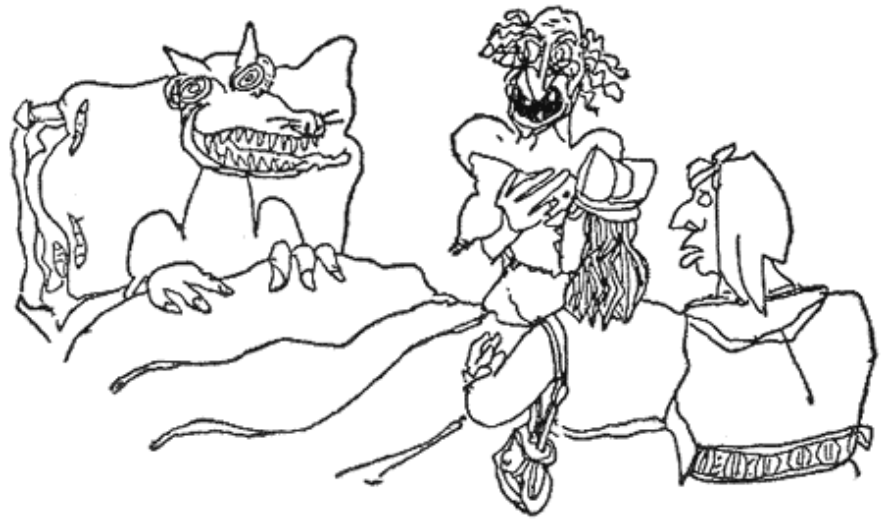


Vovozinha Vermelha era uma vovozinha que vivia cuidando de sua horta, sem se importar com a maledicência natural do mundo. Vovozinha Vermelha, assim chamada porque, quando moça, se disfarçava de velhinha pra dar cobertura a subversivos do Partido Comunista, agora continuava sendo chamada assim porque em sua horta só plantava tomates (vermelhos), pimentões (encarnados), caquis (fucsinos), beterrabas (sangue-de-boi) e cenouras (carmesins). Na verdade, a essa altura do mundialito, ela detestava política, a cor vermelha e horta, mas o que é que havia de fazer na sua idade provecta, quando o apelo da vida noturna e das orgias sexuais já estava tão longe?

De família, ao que se saiba, Vovozinha Vermelha tinha apenas Chapeuzinho Turquesa, uma neta que sempre the trazia uma cesta de pães, mel natural, arroz integral e outras macrobióticas. A macróbia agradecia à netinha, ao mesmo tempo em que Ihe invejava os guapos acompanhantes - uma hora era Frederico, outra Teodoro, outra Manfredo, outra Gervásio. "Isso é que é juventude", pensava ela, "e não a porcaria que deixei pra trás!"

Um dia, quando ia por ali assim, Chapeuzinho Turquesa acompanhada por Fagundes - encontrou um lobo, que the disse:

- Olá, tou te conhecendo? Não dançamos juntos no Vereda Tropical? 
- Sem essa - sacou Chapeuzinho. - Eu não frequento o Vereda, não moro em Niterói e esse aqui é o Ambrósio, campeão de GinDo-Ku-Fu e minha transa atual.

O lobo se fez de desentendido e disse:

- Então tá bem, vou tentar a tua avó.

- Vai com Deus, a paz e o livramento - respondeu Chapeuzinho. - E se achar um buraco, cai dentro.

E quando o lobo se afastava correndo, ela disse pro companheiro:

- Lobo falando! Parece alucinado.

E o Gin-Do-Ku-Fu respondeu:

- Alucinado não. Chegado a um alucinógeno. - E continuaram a caminhar.

Quando iam se aproximando do condomínio fechado da vó, começaram a ouvir gritos terríveis:

- Socorro! Socorro! Me acudam! Estão me violentando!

O casal correu e, quando entrou no quarto da Vovozinha Vermelha, lá estava o lobo, deitadão na cama confortável:

- Alô, garotada, olha só que orelhas enormes eu tenho. Orelhas de burro! Sabem por quê? Passei a vida comendo garotinhas e só agora descobri que caldo de galinha velha etcétera e tal e coisa... Nesse momento a Vovozinha Vermelha ia saindo do banheiro e Chapeuzinho perguntou, espantada: 
- Uau, Vovozinha, eu pensei que o lobo tinha comido a senhora! Ao que a velha gargalhou:

- Oh, netinha, como sois ingenuosa! A espécie Canis lupus há várias gerações que abandonou a via oral. E esse aí, especialmente, soube reconhecer as minhas qualidades não-dietéticas.

- Lamentável o comportamento das velhas gerações - criticou Chapeuzinho ao ouvido do companheiro. E pra vó:

- Mas então por que a senhora gritou por socorro?

- Socorro? - disse o lobo. - Quem gritou por socorro fui eu!

Moral: o melhor afrodisíaco é a carência prolongada.

FERNANDES, Millôr. Millôr online. Disponível em: http://www2.uol. com.br/millor/chapeuzi/001.htm. Acesso em: 4 jul. 2010.

A subversão proposta pelo escritor já se manifesta logo no título. A avó de Chapeuzinho é que aparece no título, e não a menina, mostrando que, nessa versão, houve a troca da protagonista. Além disso, é a avó que se apresenta portando a cor vermelha, como se esta tivesse tomado o lugar da neta na construção da história, o que será confirmado ao longo da narrativa. Outra personagem que também sofre uma inversão conceitual é o Lobo, que, já no subtítulo entre parênteses, é caracterizado como não tão mau, quebrando as expectativas quanto à semântica global do texto e aguçando a curiosidade do leitor. 
Diferentemente das outras versões, tanto as de Perrault e dos Irmãos Grimm quanto as outras de Millôr, a personagem que abre a narrativa por meio de sua descrição é a Vovozinha. Esta é descrita como uma pessoa independente e segura de si, o que se pode observar nos trechos "vivia cuidando de sua horta" e "sem se importar com a maledicência natural do mundo", ao contrário da Chapeuzinho Vermelho frágil e insegura das versões tradicionais. A atribuição da cor vermelha ao nome da Vovozinha é logo explicada pelo narrador, o qual informa sua origem com base na contextualização política em que está se envolveu na juventude, mas que agora não tinha mais razão de ser, apesar de ter mantido a fama por meio dos vegetais cultivados em sua horta. Inclusive, o apelido Vovozinha já vinha também sendo usado pela personagem desde a sua militância política.

Note-se que o narrador não menciona a cor vermelha associada à simbologia do campo semântico do comunismo, mas o leitor chega a essa conclusão a partir do conhecimento enciclopédico e de mundo, uma vez que tal associação é possível por meio da observação do uso da referida cor no âmbito do partido político citado. Além disso, a nova protagonista deixou para trás aqueles 
ideais com o amadurecimento de suas convicções. Mas, apesar de não estar mais envolvida com questões políticas e com a cor referenciada, ainda se mantinha naquele contexto praticamente por falta de opção, ou porque não havia alternativa para ocupar seu tempo, em razão da idade avançada, ou provecta, como no texto. O emprego do termo mundialito, em substituição à expressão mais comum "altura do campeonato", se refere ao nome dado a uma competição internacional em algum esporte, entre clubes ou entre seleções nacionais, com número reduzido de participantes, menor que o usual em campeonatos mundiais dessa espécie. ${ }^{2}$

Somente no segundo parágrafo é feita uma referência ao conto parodiado, já que o único parente que a senhora ainda tinha era sua neta. Esta, no caso da versão em análise, também usa um Chapeuzinho, mas de cor Turquesa, que, na simbologia das cores, remete à ideia de paz, tranquilidade, serenidade e equilíbrio. Daí por diante, outras remissões ao conto tradicional são apresentadas. É importante também observar que a mãe de Chapeuzinho não aparece nessa versão. Outro elemento inserido por Millôr nessa nova versão é a relação de alimentos, pães, mel natural, arroz integral

2 Cf. Dicionário Aulete Digital. Disponível em: http://www.aulete.com.br/mundialito. Acesso em: 30 ago. 2016. 
e outras macrobióticas, contextualizando a preocupação da vida moderna com uma alimentação mais saudável. A nova Chapeuzinho, agora Turquesa, também se diferencia do conto tradicional no que tange à inocência e à pureza, que, nesse caso, não caracterizam a personagem. Pelo contrário, a netinha de Vovozinha Vermelha se apresenta bastante volúvel, trocando de namorado a todo instante, comportamento este valorizado pela nova protagonista ao dizer que aquilo é juventude, e não a porcaria que deixou para trás. Esse comportamento pode demonstrar também uma mudança com relação à ideologia expressa nos contos de Perrault e dos Irmãos Grimm, em que a figura da avó é vista como a representação dos valores morais tradicionais.

Outra alteração em relação ao texto-fonte é vista no momento em que Chapeuzinho encontra o lobo, uma vez que, nessa versão, ela está acompanhada. Para conferir uma atmosfera despojada da linguagem coloquial, o autor usa expressões como tou, na fala do lobo, e as expressões Sem essa e minha transa atual, que também denotam a personalidade liberal da menina, uma vez que são formas coloquiais. Além disso, a personagem Chapeuzinho troca o nome do namorado, em razão da constante variação de parceiros, como já havia mencionado sua avó. Daí, então, 
como é comum nos textos de humor de Millôr Fernandes, há a inserção de um trocadilho na fala da menina: Vai com Deus, a paz e o livramento. E se achar um buraco, cai dentro, como sinal de desprezo pelo animal. O espanto diante daquela situação inusitada remete ao mundo das fábulas, quando Chapeuzinho reflete sobre o fato de estar conversando com um lobo, afirmando que ele parecia alucinado, ao que o seu companheiro completa com a frase Chegado a um alucinógeno, como forma de alusão ao uso de drogas. O autor ainda inventa uma luta chamada Gin-Do$\mathrm{Ku}-\mathrm{Fu}$, que não se encontra em nenhuma fonte consultada neste estudo, como marca da criatividade permitida para o gênero textual em análise.

A história continua guardando algumas semelhanças e diferenças com relação ao texto-fonte. Neste caso, Chapeuzinho chega acompanhada pelo namorado à casa da avó - que, na paródia em análise, fica em um condomínio fechado, e não isolada no meio da floresta - e se depara com os gritos do Lobo, acreditando serem da velha. Isso nos remete à figura do caçador da versão do conto produzida pelos Irmãos Grimm, que aqui é substituído pelo namorado da neta. Ao entrar na casa, qual a surpresa dos dois ao verem que quem gritava por socorro era o Lobo, invertendo-se a posição 
de vítima: antes a avó ou a menina; então o Lobo, até porque não existe(m) vítima(s) ou algoz na presente versão. E quem começa a sequência de descrições sobre a figura do Lobo é ele mesmo, sem que haja tempo de ser questionado. Mais uma vez, empregam-se expressões de uso coloquial como Alô, garotada e, mais adiante, uma construção bastante peculiar a essa modalidade da língua: caldo de galinha velha etcétera e tal e coisa..., atribuindo-se à fala do Lobo um aspecto evasivo, sem muita clareza de sentido.

Para surpresa dos visitantes, quem está no comando da situação é a própria Vovozinha Vermelha, que sai do banheiro deixando transparecer que houve um contato mais íntimo entre ambos, o que já tinha sido anunciado pelo Lobo e que se confirma com a reação e a resposta a Chapeuzinho Turquesa. Na resposta, a avó usa o termo ingenuosa, mais um neologismo criado por Millôr, que corresponde ao adjetivo ingênua. Ao mencionar a espécie do animal, o autor usa a fala da avó, que tem um vasto conhecimento enciclopédico, para informar o nome científico do lobo: Canis lupus. Além disso, constrói um discurso ambíguo, com conteúdo semântico voltado para a relação metafórica entre $\mathrm{o}$ ato de ingerir um alimento e o apetite sexual. E, dessa vez, quem faz o comentário crítico ao comportamento da avó 
é a Chapeuzinho, demonstrando novamente uma inversão de posições ideológicas, além de remeter também a um tipo de preconceito com relação à vida sexual das pessoas mais idosas. Nesse momento, é então revelado que quem estava verdadeiramente se sentindo em perigo era o Lobo, confirmando a inversão de papéis.

Cabe ressaltar que esta é a única versão do conto de Chapeuzinho Vermelho, entre as pesquisadas para este trabalho, que explicita a moral da história, aproximando-a ainda mais do gênero textual fábula. Desse modo, é feita uma reflexão acerca da ideia que se construiu ao longo da narrativa, ou seja, a semântica global, de que o melhor afrodisíaco é a carência prolongada. Em outros termos, a abstinência aguça ainda mais o desejo.

\section{CONCLUSÃO}

A partir do conceito de referência definido pela filosofia da linguagem (aqui representada nas palavras de Frege e Ricoeur), combinado com a teoria da iconicidade verbal de Simões, acreditamos que pode haver uma relação entre a falta de domínio das estratégias de produção de sentidos realizadas pela relação autor-texto-leitor, numa perspectiva dialógica, e as condições precárias do analfabetismo funcional. 
As estratégias de leitura construídas com base na teoria da iconicidade verbal de Simões (2009) podem orientar a identificação e a interpretação de pistas presentes na superfície textual. Combinadas com o domínio dos gêneros textuais, essas estratégias poderão proporcionar maior interação entre autor e leitor por meio de uma aproximação mais segura entre leitor e texto e auxiliar no desvendamento dos jogos sígnicos gerados pelas associações presentes (no) ou sugeridas pelo texto. E, desse modo, promover a expansão do conhecimento linguístico-enciclopédico dos sujeitos, preparando-os para uma prática sociocultural de sucesso. O próprio texto referenciado se constitui como um signo. Em outros termos, a intertextualidade funcionaria como meio de produção da semiose, tornando a referência a outros textos um processo de geração de signos que se configuram como icônico-indiciais.

Acreditamos que a base de toda educação está nos princípios apresentados ao indivíduo em desenvolvimento, ao longo de sua vida, nas relações interpessoais. Parte decisiva de sua personalidade será formada nas fases iniciais de sua vida, e então se deve aprender a reconhecer os limites impostos pela vida em sociedade.

As práticas de ensino e aprendizagem devem ser orientadas não apenas no sentido de fornecer as 
ferramentas necessárias à percepção das estratégias linguísticas presentes em todos os textos, mas também de incentivar a busca pelo conhecimento de mundo cada vez mais amplo, tornando, assim, os leitores mais proficientes e, possivelmente, preparados para a produção de seus próprios textos.

Como pudemos observar no presente artigo, há diversas formas de se encarar as questões relativas à leitura, interpretação e compreensão dos textos. A nosso ver, uma alternativa interessante para esse estudo está voltada para a teoria da iconicidade verbal (SIMÕES, 2009) como forma de se extrair do texto aquilo que ele tem de mais precioso: os sentidos possíveis. E o resgate desses sentidos está atrelado ao universo cultural tanto de quem produz o texto quanto de quem o lê. Para estes, as noções de produção textual e de leitura devem estar inseridas em uma rede intertextual, em que todos os textos já produzidos ao longo da história da humanidade funcionem ora como signos orientadores, ora como signos desorientadores, a depender da intencionalidade do autor e do texto.

Sendo assim, a formação do leitor crítico e autônomo, que seja capaz de usar seus conhecimentos armazenados na bagagem cognitiva, articulados com os conhecimentos 
linguísticos, depende de uma orientação adequada e isenta de preconceitos com relação à proveniência desses conhecimentos. Desse modo, abrem-se os horizontes para que se tenha um discernimento acerca das informações que possam ser aproveitadas, evitando-se as leituras bizarras e descontextualizadas.

\section{REFERÊNCIAS}

ALVAREZ, Luciana. Quando a escola não ensina. Revista Educação, 187. ed., nov. 2012. Disponível em: http://revistaeducacao.uol.com.br/textos/187/ quando-a-escola-nao-ensina-273079-1.asp. Acesso em: 28 nov. 2012.

ARISTÓTELES. Poética. São Paulo: Nova Cultural, 2000. (Coleção Os Pensadores).

BOURDIEU, Pierre. A economia das trocas simbólicas. Tradução de Sergio Miceli, Silvia de Almeida Prado, Sonia Miceli e Wilson Campos. São Paulo: Perspectiva, 1999.

DEELY, John. Semiótica básica. Tradução de Julio C. M. Pinto. São Paulo: Ed. Ática, 1990. (Série Princípios).

ECO, Umberto. Tratado geral de semiótica. São Paulo: Perspectiva, 1980. ECO, Umberto. Os limites da interpretação. São Paulo: Perspectiva, 2004. FREGE, Gottlob. Lógica e filosofia da linguagem. São Paulo: Editora da Universidade de São Paulo, 2009.

$\mathrm{KOCH}$, Ingedore Grünfeld Villaça. Referenciação e orientação argumentativa. In: $\mathrm{KOCH}$, Ingedore Grünfeld Villaça; MORATO, Edwiges Maria; BENTES, Anna Christina (Orgs.). Referenciação e discurso. São Paulo: Contexto, 2005. p. 33-52.

MARCUSCHI, Luiz Antônio. Produção textual, análise de gêneros e compreensão. São Paulo: Parábola, 2008.

PEIRCE, Charles Sanders. Semiótica. São Paulo: Perspectiva, 2005. 
RIBEIRO, Vera Masagão. Analfabetismo e analfabetismo funcional no Brasil. Reescrevendo a educação: propostas para um Brasil melhor. Disponível em? http://www.stellabortoni.com.br/index.php/ artigos/1231-analfabetismo-e-alfabetismo-funcional-no-brasil-49609375. Acesso em: 12 mar. 2014.

RICINO, L. A velha e boa gramática. Revista Conhecimento Prático: Língua Portuguesa, São Paulo, n. 39, 2013, p. 34-41.

RICOEUR, Paul. O mal: um desafio à filosofia e à teologia. Tradução de Maria da Piedade Eça de Almeida. Campinas, SP: Papirus, 1988.

RICOEUR, Paul. A metáfora viva. Tradução. Dion Davi Macedo São Paulo: Loyola, 2000.

RONCARATI, Cláudia. As cadeias do texto: construindo sentidos. São Paulo: Parábola Editorial, 2010.

SIMÕES, Darcilia Marindir Pinto. Semiótica e ensino: reflexões teóricometodológicas sobre o livro-sem-legenda e a redação. Rio de Janeiro: Dialogarts, 2003. (Coleção Monografias, Dissertações e Teses).

SIMÕES, Darcilia Marindir Pinto. Iconicidade e verossimilhança: semiótica aplicada ao texto verbal. Edição online. Rio de Janeiro: Dialogarts, 2007.

SIMÕES, Darcilia Marindir Pinto. Iconicidade verbal: teoria e prática. Rio de Janeiro: Dialogarts, 2009.

WAGNER, Daniel A. Alfabetização: construir o futuro. Tradução de Lólio de Lourenço de Oliveira. Brasília: SESI-DN, 2000.

WOOD JR., Thomaz. Analfabetismo funcional. Revista Carta Capital, 24 jul. 2013. Disponível em: http://www.cartacapital.com.br/revista/758/ analfabetismo-funcional-6202.html. Acesso em: 12 mar. 2014.

Elmar Rosa de Aquino é doutorado em Estudos da Linguagem, com a tese intitulada $A$ interdiscursividade/intertextualidade nas Fábulas Fabulosas de Millôr Fernandes (UERJ-2016), sob orientação da prof.a dr.a Darcilia Simões; mestrado em Língua Portuguesa, com a dissertação intitulada Que Reino é esse? - estratégias de interdiscursividade em 
Edir Macedo (UERJ-2009), sob orientação da prof.a dr.a Darcilia Simões; Membro do grupo de pesquisa Semiótica, Leitura e Produção Textual SELEPROT (CNPq), sob coordenação da prof.a dr. - Darcilia Simões; atua como supervisor de revisão da EdUERJ.

Lattes: http://lattes.cnpq.br/5509728265199697

E-mail: elmar.aquino@gmail.com 